\title{
Melting temperature versus crystallinity: new way for identification and analysis of multiple endotherms of poly(ethylene terephthalate)
}

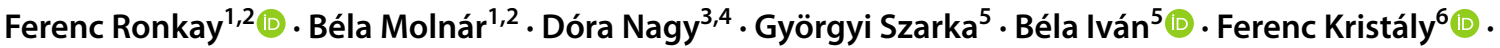 \\ Valéria Mertinger ${ }^{7}$ (D) Katalin Bocz ${ }^{8}$ (1)
}

Received: 2 April 2020 / Accepted: 14 October 2020 / Published online: 17 November 2020

(c) The Author(s) 2020

\begin{abstract}
Poly(ethylene terephthalate) (PET) materials with different molecular weights were isothermally crystallized from melt by systematically varying the temperature and duration of the treatment performed in the differential scanning calorimeter (DSC). Multiple endotherm peaks were observed on the subsequent heating thermograms that were separated from each other on the basis of their melting temperature versus crystallization temperature and melting temperature versus crystallinity function. By this new approach five sub-peak sets were identified and then comprehensively characterised. Wide-Angle X-Ray Diffraction (WAXD) analyses revealed that the identified sub-peak sets do not differ in crystalline forms. By analysing the crystallinity and the melting temperature of the sub-peak sets as a function of crystallization time, crystallization temperature and intrinsic viscosity, it was concluded that below the crystallization temperature of $460 \mathrm{~K}$ the sub-peak sets that were formed during primary or secondary crystallization transform partially or completely to a third sub-peak set during the heating run of the measurement, while above this temperature, the sub-peak set formed during primary crystallization gradually transforms to a more stable structure, with higher melting temperature. These formations and transformations are described with mathematically defined parameters as well.
\end{abstract}

Keywords Poly(ethylene terephthalate) $\cdot$ Isothermal crystallization $\cdot$ Differential scanning calorimetry $\cdot$ Multiple melting endotherm $\cdot$ Solid state polycondensation

\section{Introduction}

The usage of poly(ethylene terephthalate) (PET) still increases nowadays; in original form and as secondary raw material alike [1,2]. Besides the packaging industry, PET

Ferenc Ronkay

ronkay@pt.bme.hu; ferenc.ronkay@gmail.com

1 Material Testing Laboratory, Imsys Ltd, Mozaik Street 14/A, 1033 Budapest, Hungary

2 Department of Polymer Engineering, Faculty of Mechanical Engineering, Budapest University of Technology and Economics, Múegyetem rkp. 3, H-1111 Budapest, Hungary

3 Department of Materials, Faculty of Engineering, Imperial College London, London SW7 2BP, UK

4 Department of Physical Chemistry and Materials Science, Laboratory of Plastics and Rubber Technology, Faculty of Chemical Technology and Biotechnology, Budapest University of Technology and Economics, Múegyetem rkp. 3, 1111 Budapest, Hungary is increasingly used as a technical material thanks to the achievements of the material developments (Solid State Polycondensation reaction (SSP) or chain extender additives) and the advancements in the processing technologies (foam forming, 3D printing) [3-7]. Regarding applicability

5 Polymer Chemistry Research Group, Institute of Materials and Environmental Chemistry, Research Centre for Natural Sciences, Magyar tudósok krt. 2, 1117 Budapest, Hungary

6 Faculty of Earth Science and Engineering, University of Miskolc, Miskolc, Hungary

7 Institute of Physical Metallurgy, Metalforming and Nanotechnology, University of Miskolc, Miskolc, Hungary

8 Department of Organic Chemistry and Technology, Faculty of Chemical Technology and Biotechnology, Budapest University of Technology and Economics, Múegyetem rkp. 3, 1111 Budapest, Hungary 
of the final products the mechanical properties are crucial, which are greatly affected by the morphology and crystalline structure formed during processing $[8,9]$.

The morphology of the PET crystals depends primarily on the molecular structure (molecular weight distribution, type and ratio of the comonomers, etc. $[10,11]$.), however the final structure is also influenced by external factors such as cooling rate, pressure, crystallization temperature, nucleating agents, orientation, etc.[12]. The crystallization of PET can be either temperature or strain induced process [13]. Temperature induced crystallization takes place when the temperature is kept between the glass transition temperature $\left(T_{g}\right)$ and the melting temperature $\left(T_{m}\right)$. In this case, the crystallization process is determined by the change in the Helmholtz free energy. The enthalpy needed for crystallization is the sum of the change in the volume and surface enthalpy of the transition phase. The Gibbs-Thomson approach is based on a thermodynamic consideration that the melting temperature of a finite crystallite is always lower than the equilibrium melting temperature $\left(T_{m}{ }^{0}\right)$ of a theoretically infinite crystallite ('block') since with the decrease in the dimensions, the Helmholtz free energy of the surface increases [14]. By using the Gibbs-Thomson equation, the equilibrium melting temperature $T_{m}{ }^{0}$ and thus the lamella thickness can be determined [14]:

$l_{c}\left(T_{m}\right)=\left[\left(1-\frac{T_{m}}{T_{m}^{0}}\right) \frac{\Delta h_{m V}}{2 \cdot \sigma_{e}}\right]^{-1}$

where $l_{c}[\mathrm{~m}]$ is the lamella thickness; $T_{m}[\mathrm{~K}]$ is the melting temperature; $T_{m}{ }^{0}[\mathrm{~K}]$ is the equilibrium melting temperature of the infinite crystallite $(564 \mathrm{~K}) ; \sigma_{e}$ is the surface energy of the folding plane $\left(0.106 \mathrm{~J} / \mathrm{m}^{2}\right)$; and $\Delta h_{m V}$ is the volumetric melting enthalpy $\left(2.1^{*} 10^{8} \mathrm{~J} / \mathrm{m}^{3}\right)$. (The data for PET material are from the research of Lu and Hay [15].) The condition for the application of this method is that the dimension of the parental plane of the lamella is large enough compared to the lateral plane. Furthermore, the lamellar thickness should be determined right before the melting temperature of the lamella. If the measurement of the lamellar thickness occurs at the crystallization temperature or its immediate surrounding then the crystallite can reorder, i.e. melt and recrystallize, and get thicker during the differential scanning calorimeter measurement (DSC).

Another significant relation has been derived by Hoffman and Weeks $(\mathrm{H}-\mathrm{W})$ giving a connection between the observed melting temperature $T_{m, o b s}$, the crystallization temperature $T_{c}$ and the equilibrium melting temperature $T_{m}{ }^{0}$ of the examined polymer. The equation assumes an obligate relationship between the lamellar thickness and the melting temperature of the polymer. According to this method, the melting temperatures of the material, previously isothermally crystallized at different temperatures, are plotted against the applied crystallization temperatures. Then, the intersection of the thus obtained Eq. 2 should be determined using the $T_{m}=T_{c}$ first degree equilibrium equation:

$T_{m, o b s}=\frac{T_{c}}{\gamma}+T_{m}^{0}\left(1-\frac{1}{\gamma}\right)$

where $\gamma[-]$ is the lamella thickening coefficient, which is the reciprocal of the slope of the H-W line. This theory assumes that the $\gamma$ is a constant.

The slope indicates the stabilization mechanism of the secondary nucleation according to Eq. 3 [16]:

$H-$ Wslope $=\left[\frac{1}{\gamma\left(1+\frac{1}{\beta}\right)} \frac{\sigma_{e, \text { crystal }} \Delta s_{\text {nuclei }}}{\sigma_{e, \text { nuclei }} \Delta s_{\text {crystal }}}\right]$

where $H$-W slope [-] is the slope of the Hoffman-Weeks curve, $\gamma[-]$ is the lamella thickening coefficient, $\beta[-]$ is the lamella widening coefficient, $\Delta s_{\text {nuclei }}[\mathrm{J} / \mathrm{K}]$ is the entropy change per unit volume of the secondary nuclei having a finite width during melting; $\Delta s_{\text {crysal }}[\mathrm{J} / \mathrm{K}]$ is the entropy change per unit volume of the lamellar crystals with infinite width during melting; $\sigma_{e}\left[\mathrm{~J} / \mathrm{m}^{2}\right]$ is the interfacial free energy of the folded surface.

Presuming that $\sigma_{e, \text { crystal }} \Delta s_{\text {nuclei }} \approx \sigma_{e, \text { nuclei }} \Delta s_{\text {crystal }}$, then the $H$-W slope is determined primarily by the lamellar thickening and widening coefficients [16]. If there is no lamellar thickening $(\gamma \approx 1)$ than the slope approximates to 1 if $\beta>>1$. This describes those processes when only few nuclei are formed, their collision is less likely, and therefore stabilization by widening of the crystallites is statistically more likely than by coalescence.

To describe the kinetics of isothermal crystallization the Avrami or, for modeling the secondary crystallization, the Lauritzen-Hoffman $(\mathrm{L}-\mathrm{H})$ methods are generally used. Lately, the Strobl model is also used to model the chain organization [17]. This model considers that the main principle of the crystal organization process is not the chain folding, but a three-step "packaging" process, during which firstly a mesomorph phase take shape by connecting the chain segments, then with the lateral growth of the surface crystallite layers are created, the coalescence of which forms the crystalline phase.

Wurm and Schick [18] concluded that the fundamental difference between the $\mathrm{L}-\mathrm{H}$ and the Strobl models is that the L-H model assumes the final lamella thickness to be formed already at the beginning of the crystallization process that determines the melting temperature. However, according to the Strobl model, the final thickness of the lamella is gradually reached with the stabilization taking place behind the front line of spreading. During the stabilization process, the whole crystal surface (including the intra-lamella surfaces) 
decreases thus the surface energy also decreases, therefore, according to the Gibbs-Thomson equation, the melting temperature gradually increases. The experimental results of this research group confirmed the Strobl model.

Lu et al. [15] analysed the kinetics of the isothermal crystallization of PET. The maximum growth rate of the polymer crystallites, calculated from the measured half-life, was observed in the range of $430-450 \mathrm{~K}$.

Van Antwerpen and Van Krevelen [19] followed the crystallization of PET with different molecular weights by analysing the spherulite growth rate as a function of temperature. It was concluded from the results of the crystallization processes, starting from either glass or melt phase, that the temperature of the maximum growth rate does not depend on the average molecular weight. However, between 410$490 \mathrm{~K}$ the growth rate was found to significantly decrease with the increase of the molecular weight.

The multiple melting peaks of PET, observable after isothermal crystallization, have been evinced and researched for more than 50 years. This phenomenon is basically explained in two ways [20]: in the first case, the different melting peaks are assumed to be associated with different morphological spherulite structures, in the other case melting and recrystallization of the initial crystallite population, accompanied with growth and perfection of the crystallites formed at low temperatures, is suspected. It has to be noted that besides the commonly used DSC, there are other techniques to disclose the origin of the multi-peaked endotherms of PET. Among others, different types of advanced DSC methods, such as temperature modulated DSC [21, 22], ultrafast chip calorimetry or nanocalorimetry, which can reach even a $10^{3}-10^{4} \mathrm{~K} / \mathrm{s}$ heating rate [23], or Differential Thermal Analysis (DTA) [24] can be mentioned. Methods that are based on X-ray diffraction, Wide-Angle X-ray Diffraction (WAXD), SmallAngle X-ray Scattering (SAXS) can be used as well. The calorimetric and the X-ray scattering methods can even be used in-situ. Melnikov et al. [25]. developed an in-situ nano-focus X-ray scattering and nanocalorimetry equipment and revealed that in case of semirigid-chain polymers the multiple melting behaviour is not necessarily coupled to the melting-recrystallization processes. Other methods can give some information about the crystallinity structure, e.g. polarised optical microscopy [26] or FTIR [27].

The extracts of explanations of the multi-peaked endotherm curves and applied measurement procedures found in literature are summarized in Table 1.

It can be established that in former publications only the peaks representing the higher melting temperatures $[24,28,29]$ were analysed presuming that the differences in the structure of molecular ordering are responsible for the different melting temperatures. Then evidence was also found for the recrystallization occurring during the DSC measurement. Later on three melting peaks were examined
$[20,22,31,32,34]$ and for the last 20 years it has been widely accepted that the I. peak corresponds to the melting of the imperfect lamellas (formed during secondary crystallization), the II. peak is the result of the time and temperature dependent isothermal crystallization and the III. peak originates from the melting and recrystallization during the DSC measurement. The morphological explanation of the different peaks, however, varies in the different researches (Table 1). In recent investigations, the multiple melting peak phenomenon was not explained by analysing the melting peaks separately but by analysing the crystallization processes occurring in different isothermal temperature ranges with a unified approach [26].

The aim of this research is to investigate the morphology of isothermally crystallized PET and to qualitatively analyse the multiple melting peaks as a function of duration and temperature of isothermal crystallization, and also in relation to the intrinsic viscosity $(I V)$ representing the average molecular weight. The effect of the heating rate applied during DSC measurement was considered as well. Our goal is to give an explanation for the multiple melting effects that removes conflicting issues between the former researches.

\section{Materials and methods}

\section{Materials}

NeoPET 80 (Neo Group, Lithuania) type PET granulate with an $I V$ of $0.80 \pm 0.02 \mathrm{dl} / \mathrm{g}$ was used in the experiments. The molecular weight (MW) of the material was modified in two ways:

(a) MW was increased by solid-state polycondensation (SSP). SSP reactions were performed by LabSys Evo Thermogravimeter (TGA, Setaram, France) in nitrogen atmosphere. Samples were held at $323 \mathrm{~K}$ for $15 \mathrm{~min}$ to purge the chamber with nitrogen and then heated up to the SSP temperature with a rate of $10^{\circ} \mathrm{C} / \mathrm{min}$. The applied SSP temperature was $503 \mathrm{~K}$, and the applied reaction time was $8 \mathrm{~h}$. At the end of the process the $I V$ value of the resin increased to $0.99 \pm 0.02 \mathrm{dl} / \mathrm{g}$.

(b) MW was decreased by multiple extrusions. The PET was dried for $4 \mathrm{~h}$ at $413 \mathrm{~K}$; then an LTE 26-44 (Labtech Engineering, Thailand) twin screw extruder was used for the extrusions with a rising temperature profile from 512 to $522 \mathrm{~K}$. During the second extrusion cycle, the PET was processed with the same parameters as before. After the first and the second extrusion steps the $I V$ value of the resin decreased to $0.66 \pm 0.02 \mathrm{dl} / \mathrm{g}$ and to $0.59 \pm 0.03 \mathrm{dl} / \mathrm{g}$, respectively.

Accordingly, crystallization characteristics were examined on four PET grades differing in $I V$ values. 


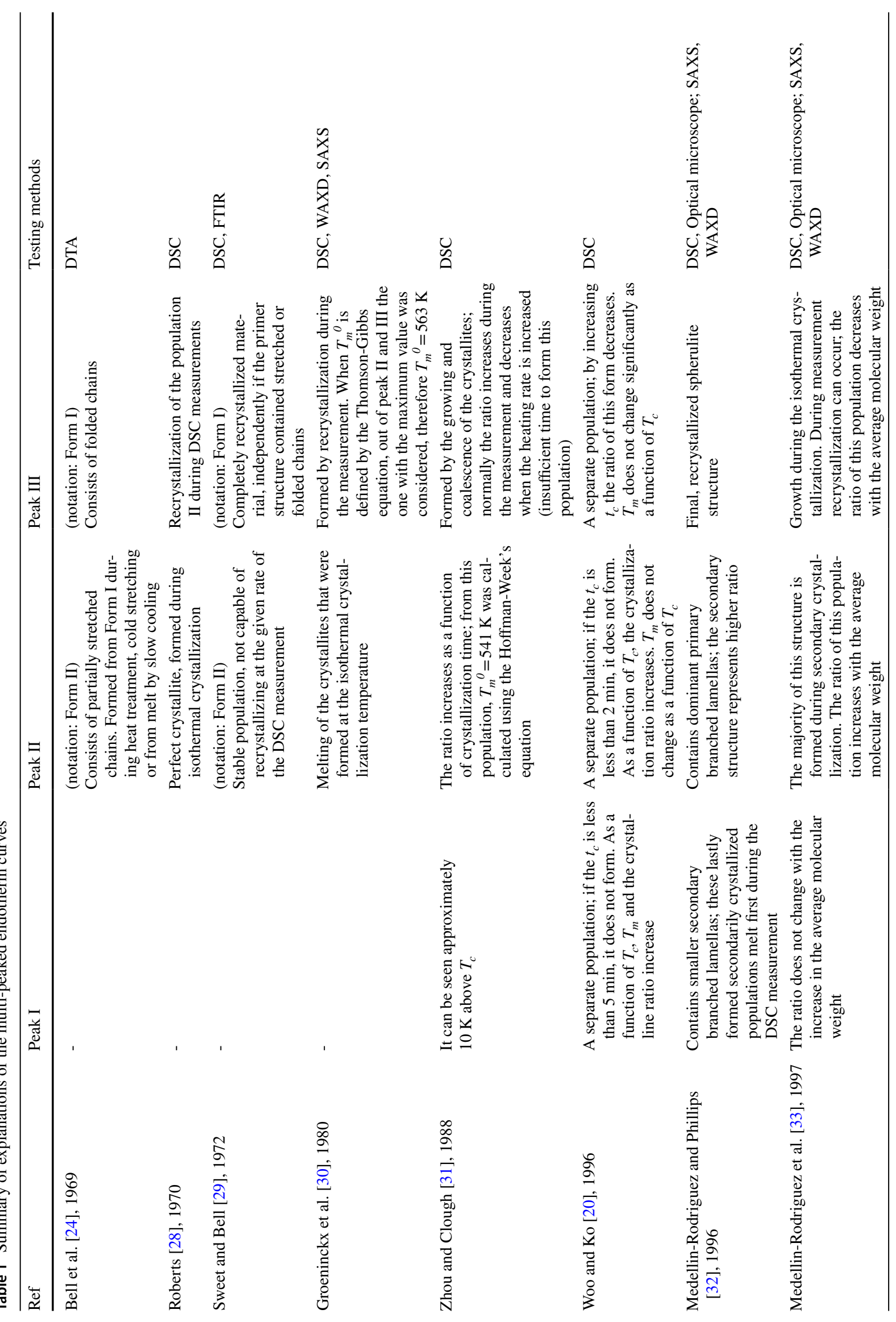




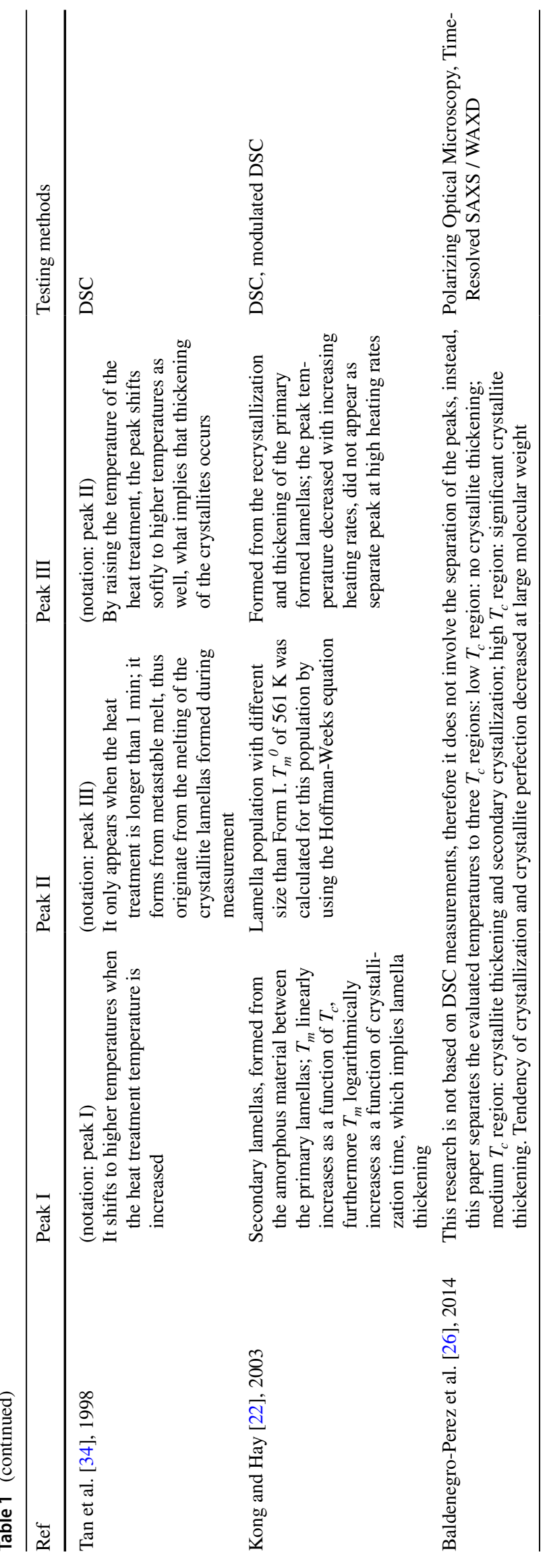

Methods

\section{Intrinsic viscosity (IV) measurements}

The average molecular weight of the PET samples was monitored by Intrinsic Viscosity measurements. The measurements were carried out according to the ASTM D4603 standard; the IV was calculated by the Billmeyer equation. The $I V$ values of the PET materials were determined using a computer controlled RPV-1 (PSL Rheotek, USA) automatic solution viscometer equipped with an optical sensor. The IV values were measured at $30{ }^{\circ} \mathrm{C}$ in a $60 / 40$ weight mixture of phenol/tetrachloroethane solvent with a concentration of $0.5 \mathrm{~g} / \mathrm{dl}$.

\section{GPC measurements}

Gel permeation chromatography (GPC) analysis was performed on four raw materials with different IV values to determine the molecular weight distribution and average molecular weights. 1,1,1,3,3,3-Hexafluoro-2-propanol (hexafluoroisopropanol, HFIP) eluent was used for the measurements. The GPC instrument was equipped with a Jetstream 2 plus thermostat, a Waters HPLC Pump 515, an HFIP-806 M column, and a Jasco RI-4035 differential refractometer detector. The measurement temperature was $40{ }^{\circ} \mathrm{C}$, the flow rate was $0.5 \mathrm{~mL} / \mathrm{min}$, and the HFIP eluent contained $5 \mathrm{mM}$ Na-trifluoroacetate. Evaluation of the chromatograms was performed by using PSS WinGPC software based on calibration with narrow molecular weight distribution poly(methyl methacrylate) standards.

\section{Isothermal crystallization}

Thermal characteristics of the samples were determined using a DSC131 EVO (Setaram, France) DSC device. The DSC measurements were performed in nitrogen atmosphere with a flow rate of $50 \mathrm{ml} / \mathrm{min}$. The weight of the examined samples was between 5-8 $\mathrm{mg}$ and two parallel measurements were carried out in all cases. On one sample the effect of 14 different crystallization temperatures $\left(T_{c}\right)$ were examined by following the program cycle presented in Fig. 1:

(a) The samples were heated up to $593 \mathrm{~K}$ with the heating rate of $10 \mathrm{~K} / \mathrm{min}$ (the melting peaks were determined from the given step) then isothermal heat treatment occurred for 2 min to erase the thermal prehistory.

(b) The samples were cooled to the given $T_{c}$ with the cooling rate of $50 \mathrm{~K} / \mathrm{min}$.

(c) The isothermal temperature was held for different times $\left(t_{c}\right)$; for $10 \mathrm{~min}, 1,3,5$ or $10 \mathrm{~h}$, depending on the program. 


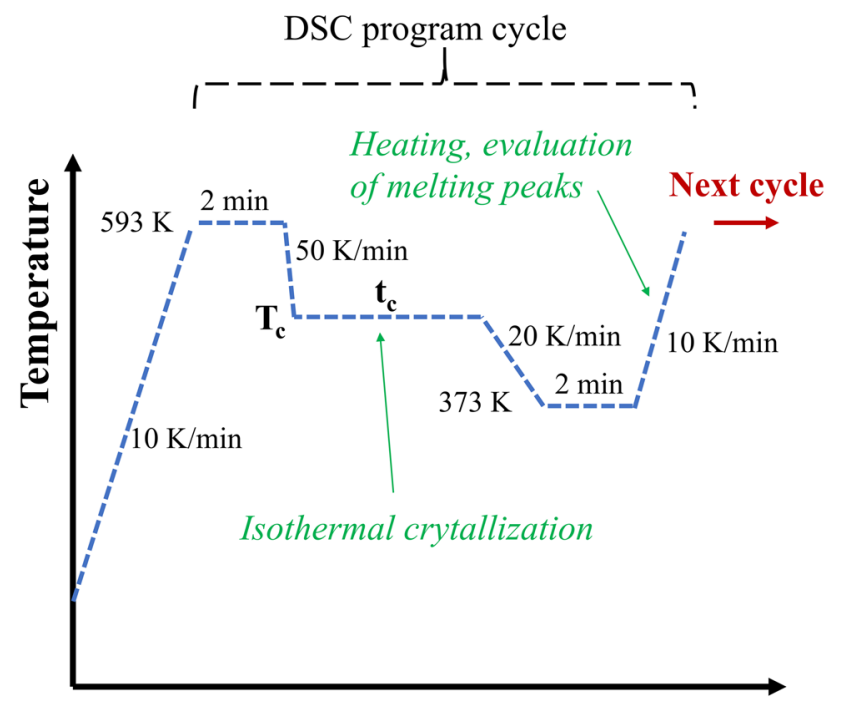

Time

Fig. 1 DSC program of cyclic isothermal crystallization

(d) The samples were cooled to $373 \mathrm{~K}$ with the cooling rate of $20 \mathrm{~K} / \mathrm{min}$ and then kept there for $2 \mathrm{~min}$, in order to stabilize the morphology.

The examined crystallization temperatures were between $493-463 \mathrm{~K}$ with steps of $5 \mathrm{~K}$ and between $463-393 \mathrm{~K}$ with steps of $10 \mathrm{~K}$. Molecular degradation during cyclic DSC program is not expected due to do the inert atmosphere and the lack of shear force. Still, control measurements were carried out to prove that the sequence of cycle
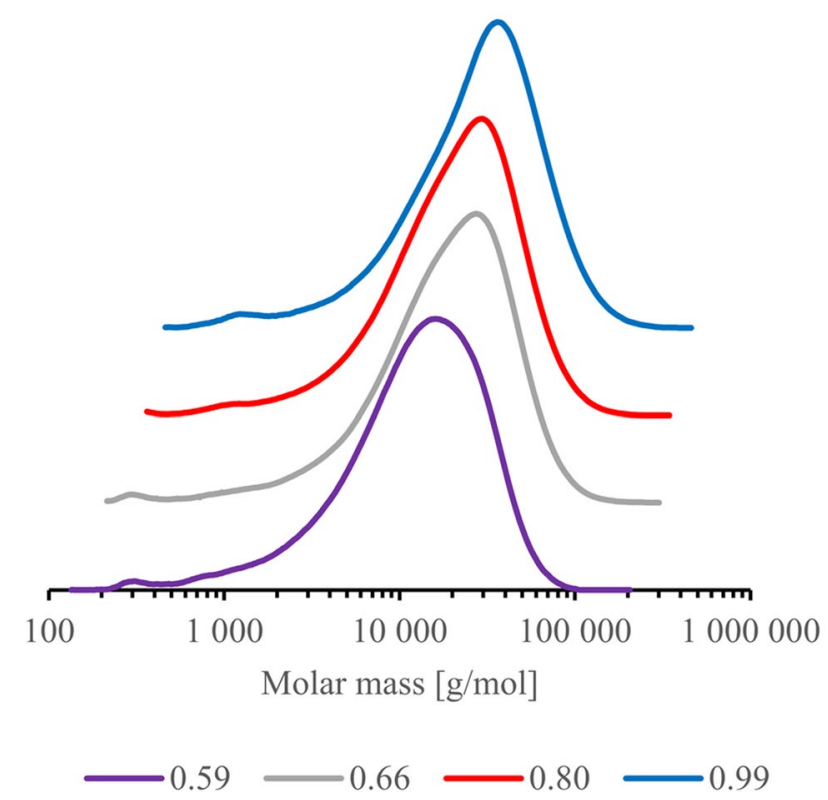

Fig. 2 The molecular weight distribution curves of the investigated PET samples
Table 2 The intrinsic viscosity (IV), the number average $\left(M_{n}\right)$ and weight average $\left(\mathrm{M}_{\mathrm{w}}\right)$ molecular weights, the peak molecular weight $\left(M_{p}\right)$ and the polydispersity index $\left(M_{w} / M_{n}\right)$ values of the investigated PET samples

\begin{tabular}{lllll}
\hline $\mathrm{IV}(\mathrm{dl} / \mathrm{g})$ & $\mathrm{M}_{\mathrm{n}}(\mathrm{g} / \mathrm{mol})$ & $\mathrm{M}_{\mathrm{w}}(\mathrm{g} / \mathrm{mol})$ & $\mathrm{M}_{\text {peak }}$ & $\mathrm{PDI}\left(\mathrm{M}_{\mathrm{w}} / \mathrm{M}_{\mathrm{n}}\right)$ \\
\hline 0.59 & 6950 & 16900 & 17150 & 2.43 \\
0.66 & 9950 & 25500 & 28900 & 2.56 \\
0.80 & 10100 & 27400 & 30300 & 2.71 \\
0.99 & 15300 & 38200 & 38100 & 2.50 \\
\hline
\end{tabular}

elements does not affect the DSC results, i.e. the last steps were performed with a material of the same quality as used in the whole cyclic program, and then compared. Standard deviation between the values of original and reverse cycle elements were between $0.7-1.4 \mathrm{~K}$ (melting temperature) and $0.3-2.4 \%$ (crystallinity) in the case of different subpeaks. (Detailed results of control measurements can be found in the Supplementary Material I.)

Limitation of the DSC measurement is that the morphological structure - formed during the previous isothermal crystallization - cannot be analysed independently: during the DSC measurement the structure can change and researchers could only analyse the modified crystalline structure. The modifying effect of the different heating rates is usually analysed by comparison; having considered that if the heating rate is fast then

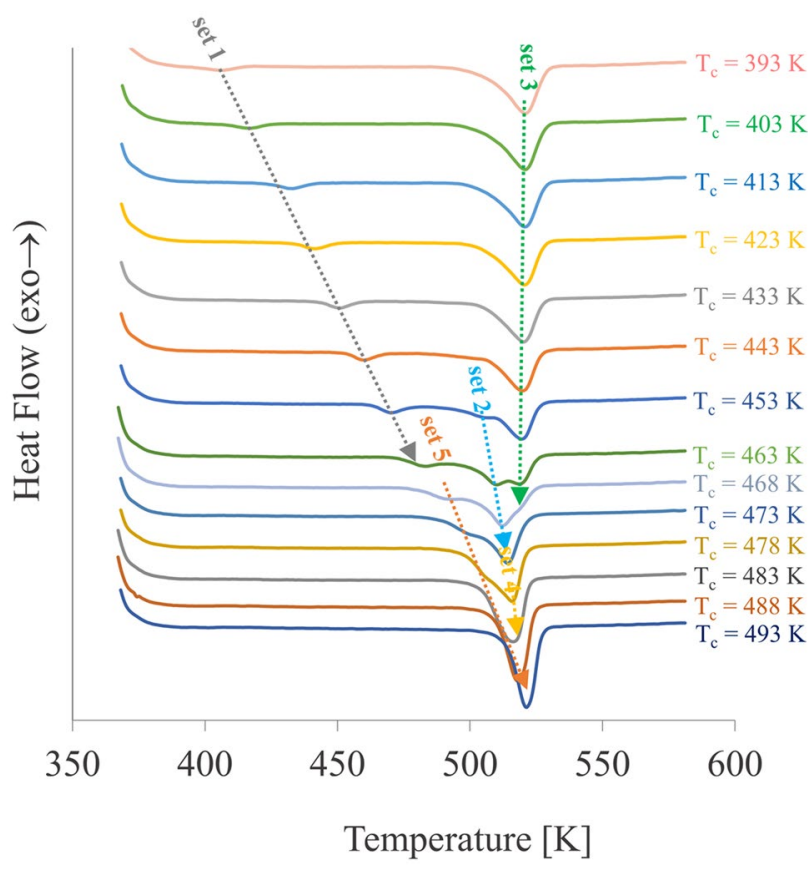

Fig. 3 DSC thermograms of original PET (IV $=0.80 \mathrm{dl} / \mathrm{g}$ ) after onehour isothermal crystallization at different temperatures. The classification of the sub-peak-sets is also indicated 
Fig. 4 Typical functions of the sub-peak sets. Legends mark the number of sub-peak sets (a) $T_{m}$ vs $T_{c}(I V=0.80 \mathrm{dl} / \mathrm{g}$; $\left.t_{c}=10 \mathrm{~min}\right)$. (b) $T_{m} \mathrm{vs} T_{c}$ $\left(I V=0.80 \mathrm{dl} / \mathrm{g} ; t_{c}=5 \mathrm{~h}\right)$. (c) $T_{m}$ vs $\chi(I V=0.80 \mathrm{dl} / \mathrm{g}$; $t_{c}=10 \mathrm{~min}$ ). (d) $T_{m}$ vs $\chi$ $\left(\mathrm{IV}=0.80 \mathrm{dl} / \mathrm{g} ; \mathrm{t}_{\mathrm{c}}=5 \mathrm{~h}\right)$. (e) $\chi \mathrm{vs}$ $T_{c}\left(I V=0.80 \mathrm{dl} / \mathrm{g} ; t_{c}=10 \mathrm{~min}\right)$. (f) $\chi$ vs $T_{c}\left(I V=0.80 \mathrm{dl} / \mathrm{g} ; t_{c}=\right.$ $5 \mathrm{~h})$
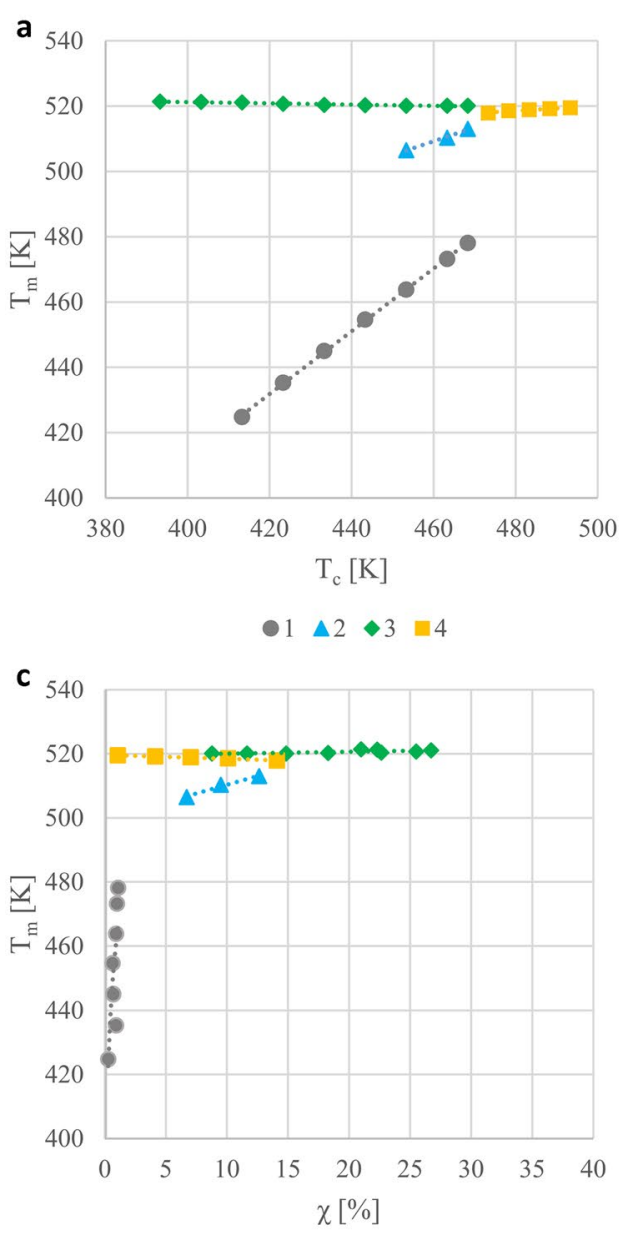

- $1 \Delta 2 \diamond 3 \square 4$

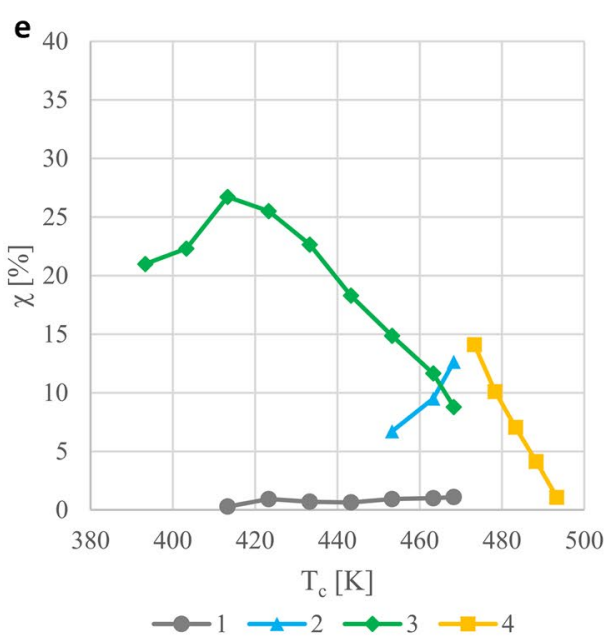

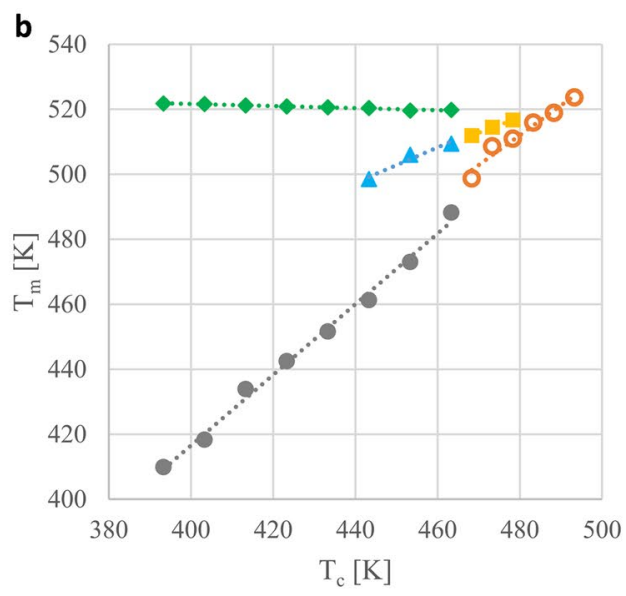

- $1 \Delta 2 \diamond 3 \square 4$ o5

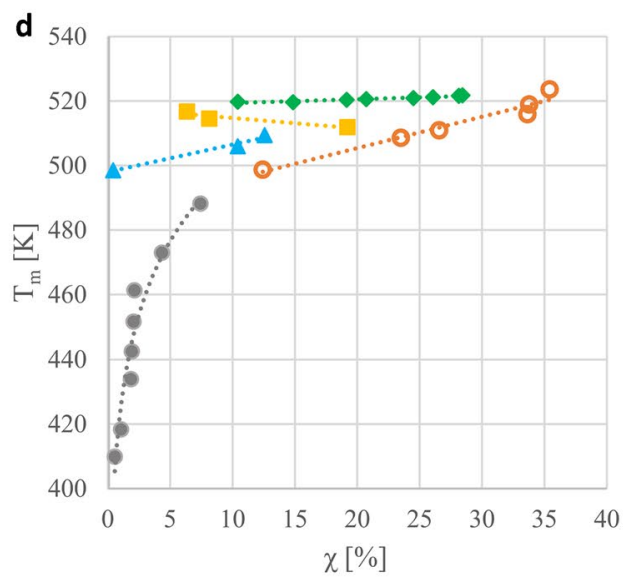

- $1 \Delta 2 \diamond 3 \square 405$

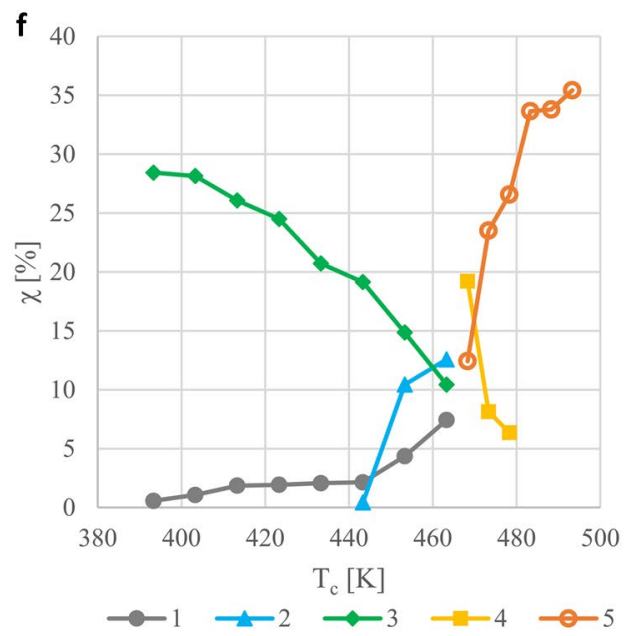

there is less time for the structure to change. Therefore, the effect of the heating rate on the detected endotherm peaks was analysed in our case as well. For this purpose, the used DSC cycle is almost the same as described previously, except that the samples were heated until $593 \mathrm{~K}$ with different heating rates $(5,10,15,20$ or $25 \mathrm{~K} / \mathrm{min})$, then cooled to one of the three given isothermal crystallization temperatures $(423,453$ or $483 \mathrm{~K}$ ) and held there for $10 \mathrm{~min}, 1,3,5$ or $10 \mathrm{~h}$, respectively. These measurements were performed only on the samples with $I V$ value of $0.80 \mathrm{dl} / \mathrm{g}$. 

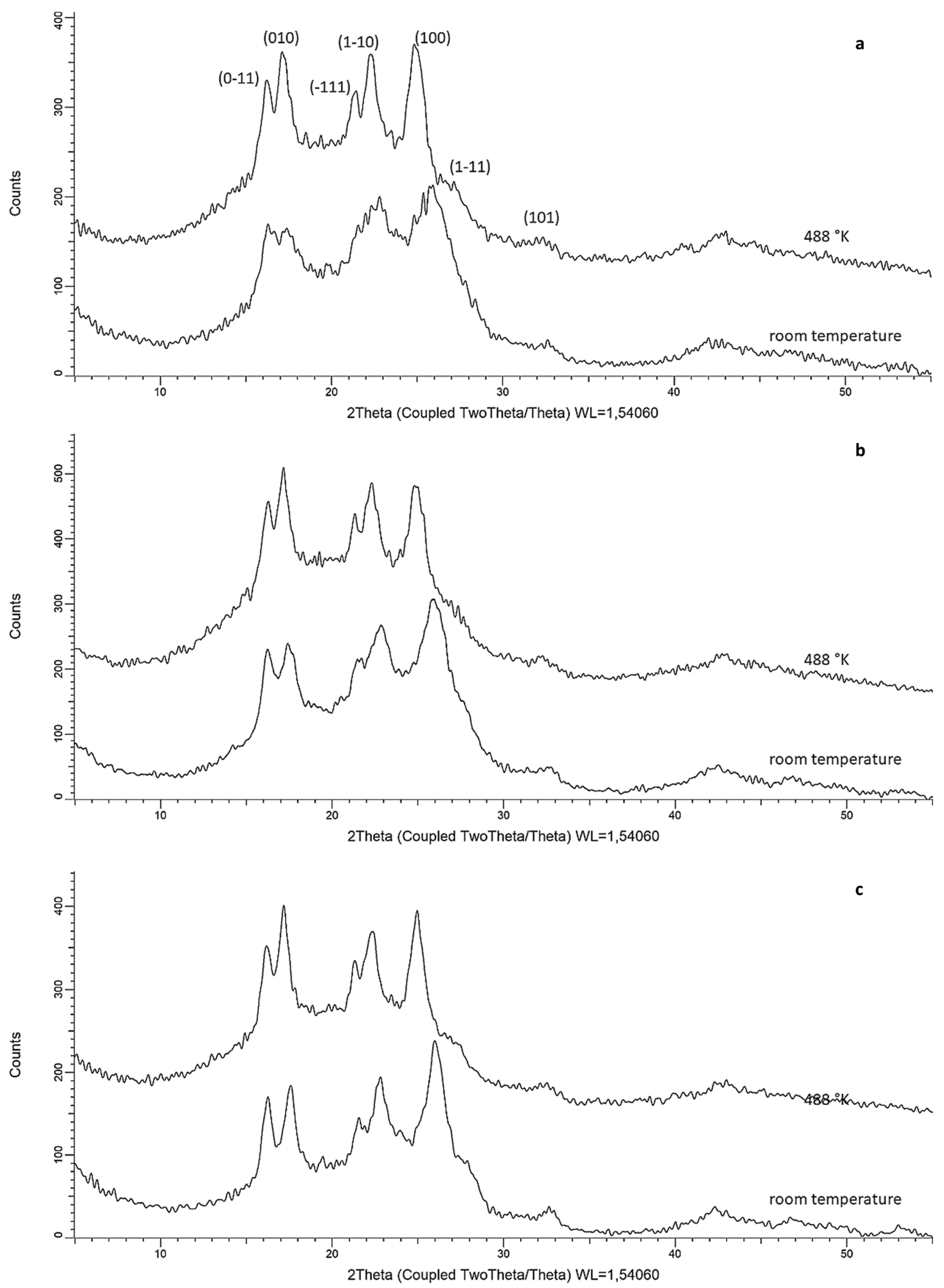
4Fig. 5 WAXD spectra at room temperature and at $488 \mathrm{~K}$. (a) $\mathrm{IV}=0.80 \mathrm{dl} / \mathrm{g} ; \mathrm{tc}=10 \mathrm{~h} ; \mathrm{Tc}=423 \mathrm{~K} ;(\mathbf{b}) \mathrm{IV}=0.80 \mathrm{dl} / \mathrm{g} ; \mathrm{tc}=10 \mathrm{~h}$; $\mathrm{Tc}=453 \mathrm{~K} ;(\mathbf{c}) \mathrm{IV}=0.80 \mathrm{dl} / \mathrm{g} ; \mathrm{tc}=10 \mathrm{~h} ; \mathrm{Tc}=483 \mathrm{~K}$;

\section{WAXD measurements}

WAXD analyses were performed on samples with an IV value of $0.80 \mathrm{dl} / \mathrm{g}$ after crystallization at 423,453 and $483 \mathrm{~K}$ for $10 \mathrm{~h}$. WAXD tests were performed on all three samples at two temperatures (room temperature and $488 \mathrm{~K}$ ) with the following parameters: The samples were investigated on a Bruker D8 Discover instrument, with $\mathrm{Cu} \mathrm{K}$-alpha radiation (40 kV and $40 \mathrm{~mA}$ generator settings) in parallel beam geometry (with Göbel mirror) using a HTK $1200 \mathrm{~N}$ heating chamber and a LynxEye XE-T energy dispersive detector in high resolution $0 \mathrm{D}$ mode. The heating was run with $10^{\circ} \mathrm{C} /$ min rate in static air atmosphere. Measurements were carried out in the $5-55^{\circ}\left(2\right.$ Theta) range with $0.014^{\circ}$ (2Theta) $/ 240 \mathrm{~s}$ steps. The peaks of PET were identified using the work of Wang et al. [35]. Crystallinity degree was determined by applying two amorphous humps according to Wang et al. (2000) and fitting the crystalline part of the pattern with individual peaks. Crystallite size for the individual peaks was calculated from the peak broadening as integral breadth corrected for the instrumental broadening, using the Scherrer formula. Integral breadth values were extracted from the measured pattern after deconvolution with empirical instrumental parametrization on NIST SRM 640d Si powder, fitting the background by 4th degree Tschebysehv polynomial function. XRD measurements were carried out in the 3DLab Fine Structure Analysis laboratory.

\section{Results and discussion}

\section{Molecular weight analysis}

The molecular weight distributions of the four PET materials, as determined by GPC measurements, are displayed in Fig. 2, while the characteristic average molecular weight (MW) and the peak MW values are shown in Table 2.

It can be seen in Table 2 that the number average molecular weight $\left(\mathrm{M}_{\mathrm{n}}\right)$ of the used PET materials ranges from 6950 to $15300 \mathrm{~g} / \mathrm{mol}$ and the weight average molecular weight $\left(\mathrm{M}_{\mathrm{w}}\right)$ ranges from 16900 to $38200 \mathrm{~g} / \mathrm{mol}$. As the polydispersity index $\left(\mathrm{PDI}=\mathrm{M}_{\mathrm{w}} / \mathrm{M}_{\mathrm{n}}\right)$, which characterizes the width of the molecular weight distribution, differs only slightly between the tested substances (its value varies between 2.43 and 2.71) it was concluded that the difference between the molecular weight distribution of the materials has negligible effect on the examined multiple melting peaks or crystalline formations, on the one hand. On the other hand, the molecular weights show acceptable correlation with the IV values. As the IV value is widely used in the literature and shows strong correlation with the average molecular weight [36, 37], the IV value was decided to be used hereinafter for characterization of the PET materials.

\section{Melting peak separation}

Figure 3 shows a typical group of DSC curves obtained from original PET samples with an $I V$ value of $0.80 \mathrm{dl} / \mathrm{g}$.
Table 3 Crystallinity and structural parameters at room temperature and at $488 \mathrm{~K}$

\begin{tabular}{|c|c|c|c|c|c|c|}
\hline & \multicolumn{2}{|c|}{$\begin{array}{l}I V=0.80 \mathrm{dl} / g ; t_{c}=10 \mathrm{~h} \\
T_{c}=423 \mathrm{~K}\end{array}$} & \multicolumn{2}{|c|}{$\begin{array}{l}I V=0.80 \mathrm{dl} / g ; t_{c}=10 \mathrm{~h} \\
T_{c}=453 \mathrm{~K}\end{array}$} & \multicolumn{2}{|c|}{$\begin{array}{l}I V=0.80 \mathrm{dl} / \mathrm{g} \\
t_{c}=10 \mathrm{~h} \\
\mathrm{~T}_{c}=483 \mathrm{~K}\end{array}$} \\
\hline & room temp & $488 \mathrm{~K}$ & room temp & $488 \mathrm{~K}$ & room temp & $488 \mathrm{~K}$ \\
\hline Crystallinity [\%] from WAXD & 27 & 37 & 31 & 32 & 29 & 38 \\
\hline \multirow[t]{2}{*}{ Crystallinity [\%] from DSC } & 22 & & 25 & & 32 & \\
\hline & \multicolumn{4}{|c|}{ Crystallite size (nm) } & & \\
\hline $\mathrm{D}_{(0-11)}$ & 10 & 15 & 13 & 15 & 15 & 16 \\
\hline $\mathrm{D}_{(010)}$ & 5 & 13 & 9 & 14 & 12 & 14 \\
\hline $\mathrm{D}_{(-111)}$ & 19 & 15 & 13 & 30 & 23 & 25 \\
\hline $\mathrm{D}_{(1-10)}$ & 6 & 12 & 7 & 9 & 10 & 10 \\
\hline $\mathrm{D}_{(100)}$ & 5 & 10 & 5 & 6 & 8 & 21 \\
\hline$*$ & 6 & 8 & 5 & 7 & 5 & 8 \\
\hline $\mathrm{D}_{(1-11)}$ & 8 & 5 & 9 & 5 & 10 & 5 \\
\hline $\mathrm{D}_{(101)}$ & 6 & 5 & 6 & 5 & 8 & 5 \\
\hline$*$ & 5 & 8 & 5 & 9 & 5 & 9 \\
\hline$*$ & 5 & 10 & 5 & 5 & 5 & 7 \\
\hline
\end{tabular}


Fig. 6 Evaluation scheme of sub-peak sets

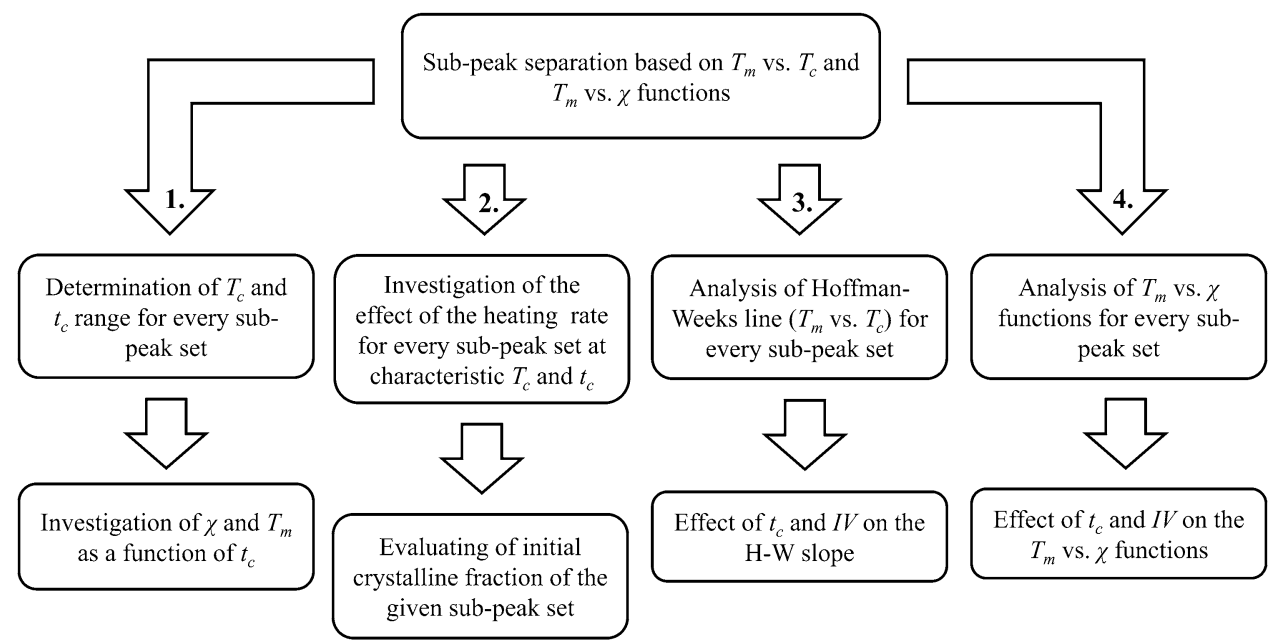

After reaching the given isothermal crystallization temperatures (393-493 K), the crystallization time was $1 \mathrm{~h}$.

Tangential sigmoid baseline was fitted on the endotherm peaks of the curves, and then the combined melting peaks were separated by the Calisto (Setaram, France) software. This program determines all the required parameters for Eq. 4 in the case of all sub-peaks:

$y=\operatorname{Aexp}\left[-\ln (2)\left[\frac{\ln \left(1+2 D \frac{x-B}{C}\right)}{D}\right]^{2}\right]$

where $A[\mathrm{~mW} / \mathrm{g}]$ is the amplitude; $B[\mathrm{~K}]$ is the position; $C$ $[\mathrm{K}]$ is the halfwidth and $D[-]$ is the asymmetry of the fitted Gaussian curve.

Crystallinity $(\chi)$ of the endotherm sub-peaks was calculated according to Eq. 5:
$\chi[\%]=\frac{\Delta H_{m}}{\Delta H_{m}{ }^{0}} * 100 \%$

where $\Delta H_{m}[\mathrm{~J} / \mathrm{g}]$ is the peak area (melting enthalpy) and $\Delta H_{m}{ }^{0}[\mathrm{~J} / \mathrm{g}]$ is the melting enthalpy of a perfect PET crystal equal to $140.1 \mathrm{~J} / \mathrm{g}$ [38].

When $T_{m}$ is displayed as a function of $T_{c}$, different linear trends can be seen in the diagrams (Fig. 4a and $4 b$ ). The trends were isolated from the different sets of points and thus so-called sub-peak sets were formed. In those cases, when the individual set points overlapped with each other, the points of the $T_{m}$ vs. $\chi$ diagrams were analysed to decide which point belongs to which set (Fig. 4c and 4d). Based on the two parallel measurements the average standard deviation (SD) of $T_{m}$ of subpeaks was $0.4 \mathrm{~K}$, the maximum SD of $T_{m}$ of sub-peaks was $1.4 \mathrm{~K}$, the average SD of $\chi$ of sub-peaks was $1.4 \%$, the maximum SD of $\chi$ of sub-peaks was $3.3 \%$. The $\chi$ vs. $T_{m}$ diagrams show similarity with the Thomson-Gibbs
Fig. 7 Dependence of $\chi_{I}$ (a) and $T_{m l}$ (b) on crystallization time and IV $\left(T_{c}=423 \mathrm{~K}\right)$
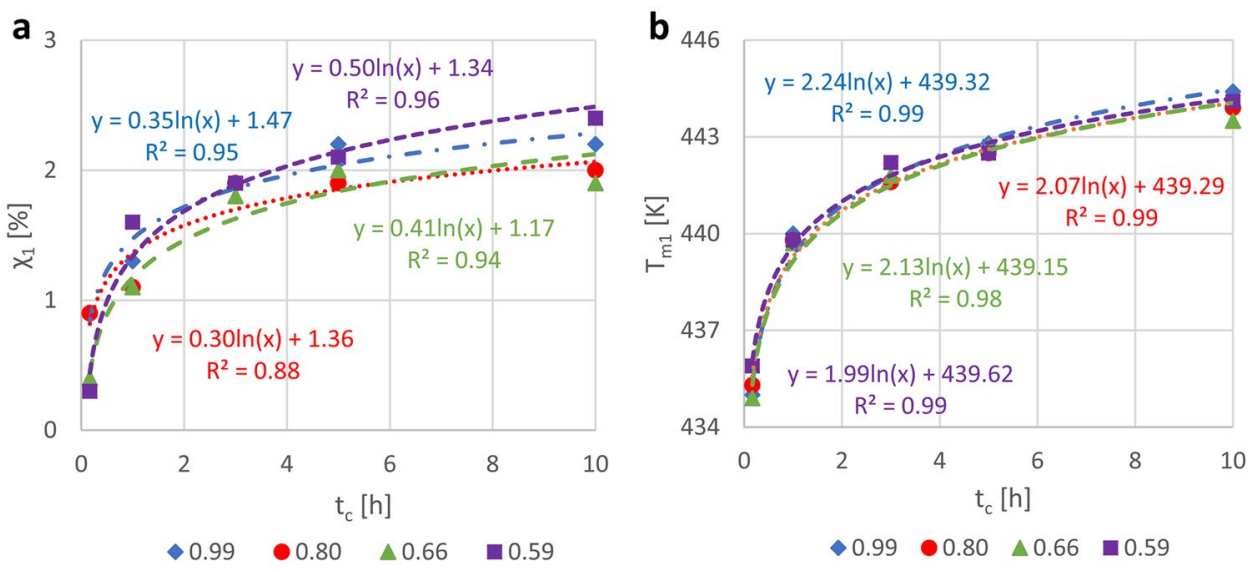
Fig. $8 \chi_{l}(\mathbf{a})$ and $T_{m l}(\mathbf{b})$ as a function of heating rate $\left(I V=0.80 \mathrm{dl} / \mathrm{g} ; T_{c}=423 \mathrm{~K}\right.$; $\left.t_{c}=3 \mathrm{~h}\right)$

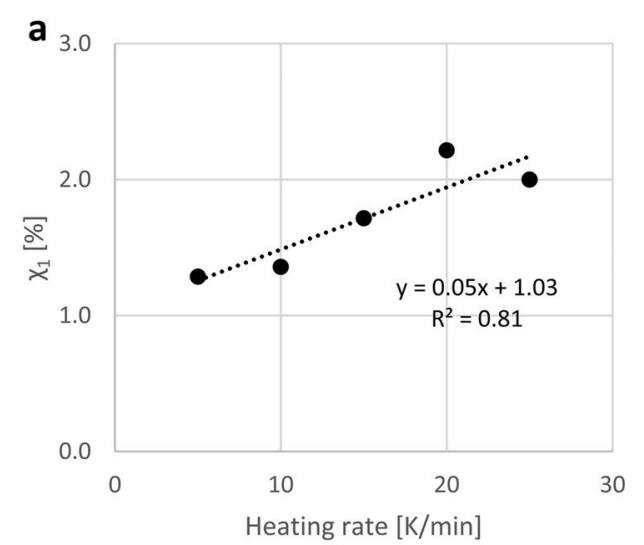

diagram when only the $y$-axis is analysed (Fig. 4e and 4f). However, the $x$-axis differs a lot: in this study on the $x$-axis not the change in the size of an individual crystallite is showed but the change in the crystallinity of the different crystalline structures.

The measured points obtained from different sets are linked together on the $\chi$ vs. $T_{c}$ diagram as well. For example, the typical functions of the original PET $(I V=0.80 \mathrm{dl} / \mathrm{g})$ after 10 min isothermal crystallization are shown in Fig. 4a, $4 \mathrm{c}$ and $4 \mathrm{e}$, while those after $5 \mathrm{~h}$ isothermal crystallization are presented in Fig. 4b, 4d and 4f, respectively. (All the diagrams can be found in the Supplementary Material II.) The functions are analysed in details in the next section.

On the obtained DSC thermograms five different subpeak sets were identified and separated. The peak separation and classification into sub-peak-sets, performed after every DSC run, is presented in Fig. 3 on the example of the DSC thermogram series of original PET $(\mathrm{IV}=0.80 \mathrm{~g} / \mathrm{dl})$ obtained after isothermal crystallisation at different temperatures. There are some similarities in the marking of the peaks with the literature $[31-33,39,40]$ for example: the $T_{m l}$ is similar to the peak I notation that represents those crystallites that were formed during secondary crystallization. However, a significant difference is that in this case the notation of the sub-peak sets did not occur simultaneously with the appearing order of the peaks, but they were sorted into the populations as coherence appeared between the peaks in the $T_{m}$ vs. $T_{c}$ and the $\chi$ vs. $T_{m}$ diagrams.

\section{Crystalline form analysis}

WAXD measurements at two different temperatures were performed in order to characterize the crystallinity and the crystalline form of the sample. During the tests the temperature high-temperature-measurement was chosen to be above the melting temperature of sub-peak set 1 , but below the melting temperature typical of sub-peaks set 2, 3, 4, and 5. The measurements were carried out with samples $I V=0.80 \mathrm{dl} / \mathrm{g}$ and $t_{c}=10 \mathrm{~h}$ where the $T_{c}$ varied from 423 to $488 \mathrm{~K}$.

The samples show a growing crystallinity and crystallite size which is indicated by the sharpening of the peaks, in the order of rising Tc measured at room temperature (Fig. 5), which is in accordance with the changing of the calculated total crystallinity values measured by DSC. For each sample, the measurement run at $488 \mathrm{~K}$
Fig. 9 (a) Crystallization temperature sensitivity of the sub-peak set 1 (slope of the $T_{m l}$ vs. $T_{c}$ function) as a function of crystallization time; (b) Parameter $b$ of the logarithmic functions as a function of the $I V$
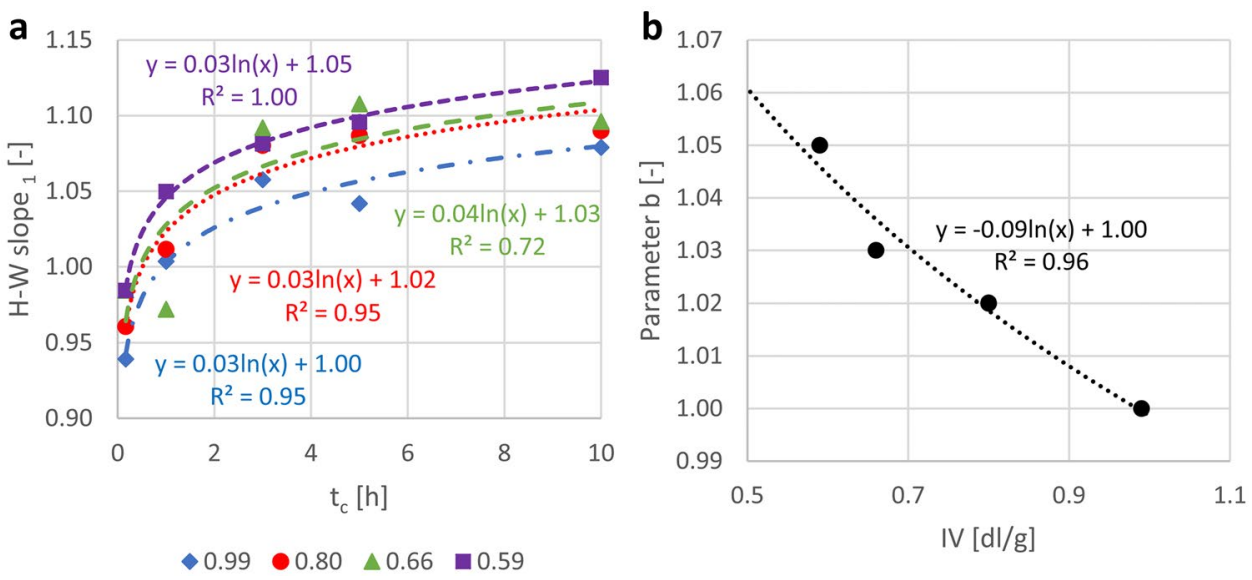
Fig. 10 (a) First parameter $c$ of the $T_{m l}$ vs. $\chi_{1}$ function as a function of $t_{c} ;(\mathbf{b})$ average of parameter $c$ (calculated at each $I V$ value) as a function of $I V$
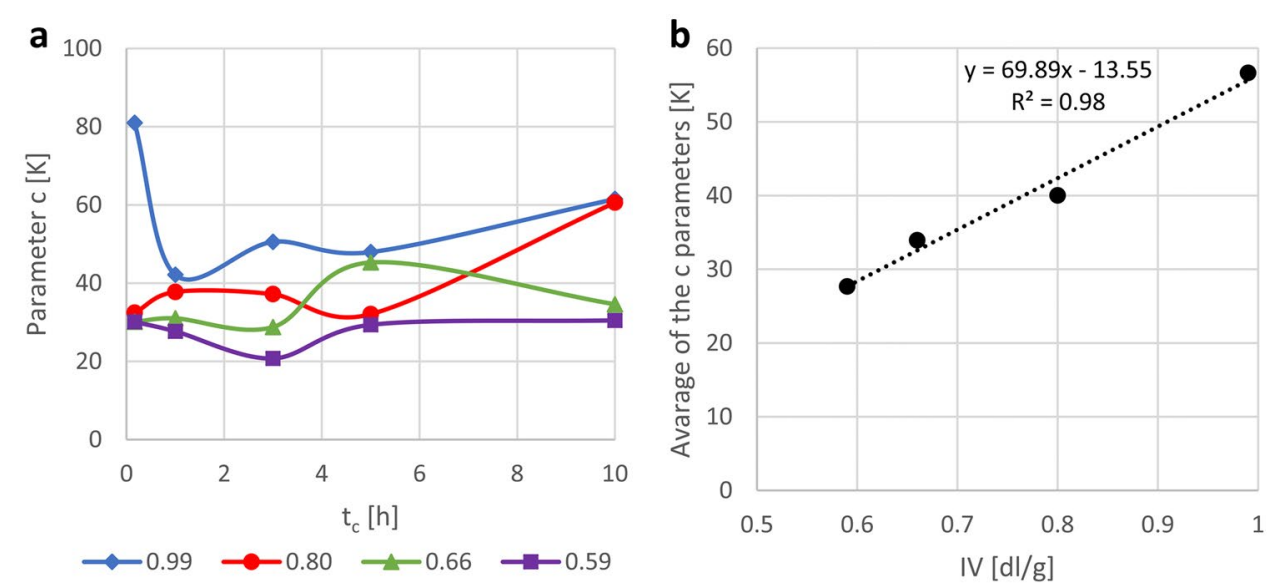

shows an improvement in crystallite size, the peaks become sharper. As no new peaks appear on the figures of WAXD measurements performed at higher temperature, it can be stated that recrystallization during which the crystalline form does not change, cannot be detected. A small shift of peak positions is observed in case of the patterns recorded at $488 \mathrm{~K}$, due to the thermal expansion of the PET lattice.

Miller indices are assigned to the peaks according to Wang et al. [35] (Table 3). However, three small intensity peaks were detected after deconvolution, which could not be indexed. These peaks are probably trace of partly modified PET structure, as a minor crystallite population associated to the main "regular" PET. A larger shift is observed for the (100) peak. It can be detected that the crystallite size

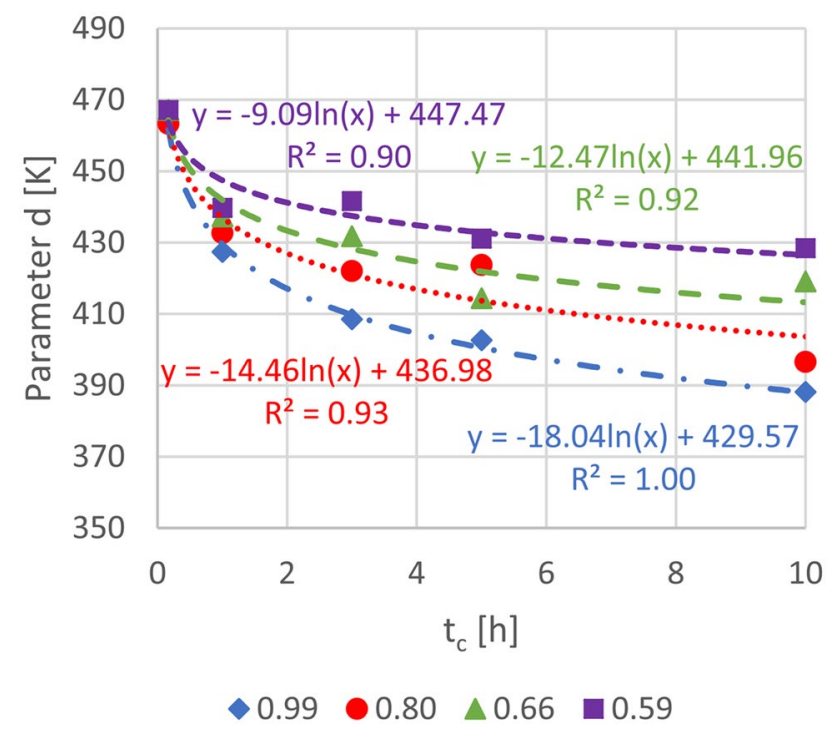

Fig. 11 Second parameter $d$ of the $T_{m l}$ vs. $\chi_{1}$ function as a function of $t_{c}$ of samples isotherm crystallized at 423 or $453 \mathrm{~K}$ differs significantly from the samples crystallized at $483 \mathrm{~K}$ in the direction of $\mathrm{D}_{(1-10)}, \mathrm{D}_{(100)}$ and $\mathrm{D}_{(101)}$ which may indicate a different nucleation process. Based on the sizes measured for the first three peaks, the crystallites tend to take isometric shape at $488 \mathrm{~K}$, while platy shape is the most characteristic at room temperature. It should be noted, that the crystallite parameters of samples isotherm crystallized at three different temperatures measured by high-temperature WAXD measurements show differences in certain directions probably due to structural differences.

\section{Analysis of the sub-peak sets}

In this part of the paper, the characteristics of the individual sub-peak sets are analysed as well as the evolution of these characteristics as a function of crystallization time, temperature, molecular weight, and heating rate are investigated (Fig. 6). Since some changes can occur in the sub-peak sets even during the DSC measurement (modification and/or transformation), the analysis of the direction and extent of these changes is of great importance. These were investigated by using different heating rates, assuming that by using faster heating rates there is less time available for the changes to occur.

In the followings, the complete evaluation method is presented in details on the example of sub-peak set 1 , while the corresponding experimental results of sub-peak sets 2-5 can be found in the Supplementary Material III.

\section{Appearance region}

The sub-peak set 1 appears typically in the crystallization temperature range of 393-468 K, however in the case of low $I V(0.59 \mathrm{dl} / \mathrm{g})$ and short crystallization time $(10 \mathrm{~min})$ this sub-peak set appears even up to the crystallization 
temperature of $493 \mathrm{~K}$. The crystallinity represented by this sub-peak set is low $(<5 \%)$. It shows some increase with increasing crystallization temperature. A logarithmic increase of crystallinity was evinced as a function of crystallization time as presented in Fig. $7 \mathrm{a}$ at a $T_{c}$ of $423 \mathrm{~K}$, which is in agreement with the findings of Woo and Ko [20]. The increase of the crystalline ratio over time implies that the sub-peak set 1 is formed during the secondary crystallization $[16,41]$. The increase in the melting temperature of the crystallites has also a logarithmic nature (Fig. 7b). The molecular weight that is represented by the $I V$ value was found to have negligible impact on the crystallinity and the melting temperature of the analysed sub-peak set.

\section{Effect of heating rate}

The crystallinity and the melting temperature of the subpeak set 1 as a function of the heating rate can be followed in Fig. $8 \mathrm{a}$ and $8 \mathrm{~b}$, respectively. The crystallinity decreases with decreasing heating rate, likely due to transformation. The melting temperature does not change significantly. Based on this, the initial crystalline fraction corresponding to subpeak set 1 is assumed to be greater, but during the measurement it was transformed into another sub-peak set.

\section{Analysis of the Hoffman-Weeks lines}

Figure 9a shows the temperature sensitivity (slope of the Hoffman-Weeks function) of the samples with different $I V$ values as a function of $t_{c}$. The slope of the functions varied between $0.90-1.20$ in the analysed time range (10 min $-10 \mathrm{~h}$ ). It can be established that the steepness of the slopes rises logarithmically in the investigated range as a function of $t_{c}$ :

$H-$ Wslope $_{1}=a * \ln \left(t_{c} / h\right)+b$

where $H$-W slope ${ }_{1}[-]$ is the slope of the function where $T_{m l}$ is plotted against $T_{c} ; t_{c}[\mathrm{~h}]$ is the crystallization time; $a$ $[-]$ and $b[-]$ are model parameters.

The displacement parameter $b$ is mainly influenced by the $I V$ value (Fig. 9b):

$b=-0.11 * I V+1.11$

According to Eq. 3 when the steepness of the $H$-W slope $_{1}$ is greater than 1 (heat treatment was longer than $1 \mathrm{~h}$ ), than in classical sense lamella thinning and/or narrowing can be assumed, which is an obvious error in thermodynamic sense. It is much more probable to presume that the crystallites with increasing crystalline ratio (as a function of time) and melting temperature are not formed by lamella folding and their sizes do not increase by lamella-thickening, but they can be described with an ordering structure (according to Strobl model), which differs from folding.

\section{Analysis of the $T_{m} v s . \chi$ function}

The melting temperature of sub-peak set 1 increases intensively as a function of crystallinity. The $T_{m l}$ as a function of $\chi_{1}$ diagram (Fig. 4e, 4f) shows a logarithmical scheme in this set:

$T_{m 1}=c * \ln \left(\chi_{1}\right)+d$

where $c[-]$ and $d[-]$ are the first and the second (displacement) parameters of the function.

The first parameter $c$ does not show a clear trend as a function of time (Fig. 10a); however, the averages of these parameters increase linearly with $I V$ (Fig. 10b):

$c=69.89 * I V-13.55$

The second parameter of the logarithmic function $(d$, displacement parameter) as a function of $T_{c}$ shows a logarithmic decrease (Fig. 11):

$d=e * \ln \left(t_{c}\right)+f$

where $e[-]$ and $f[-]$ are the first and the second (displacement) parameters of the function.

This means that in case of longer chains, accompanied with greater $I V$, with increase of the $t_{c}$, the higher crystalline ratios are associated with less intensively increasing $T_{m 1}$. Consequently, with increasing $t_{c}$ fewer molecular segments can connect parallel to the existing crystallite, especially in the case of long chains with hindered mobility.

The first parameter $e$ of Eq. 10 shows a linear decrease as a function of $I V$. Furthermore, the second parameter $f$ shows a linear correlation with the first parameter $e$. The functions are plotted in Fig. 12a and 12b, while the correlations are described by Eq. 11 and Eq. 12, respectively.

$e=-20.72 * I V+2.23$

$f=2.03 * e-466.37$

It can be concluded from Eqs.(8, 9, 10, 11 and 12) that in the case of sub-peak set 1 , the $T_{m l}$ depends on the crystalline ratio, the $I V$ and the $t_{c}$ as well:

$$
\begin{aligned}
T_{m 1} & =(69.89 * I V-13.55) \ln \left(\chi_{1}\right) \\
& +(2.23-20.72 * I V) \ln \left(t_{c} / h\right)-42.66 * I V+470.9
\end{aligned}
$$


Fig. 12 (a) First parameter $e$ of the $d$ vs. $t_{c}$ function as a function of $I V$; (b) the connection between the first $e$ and the second $f$ parameters
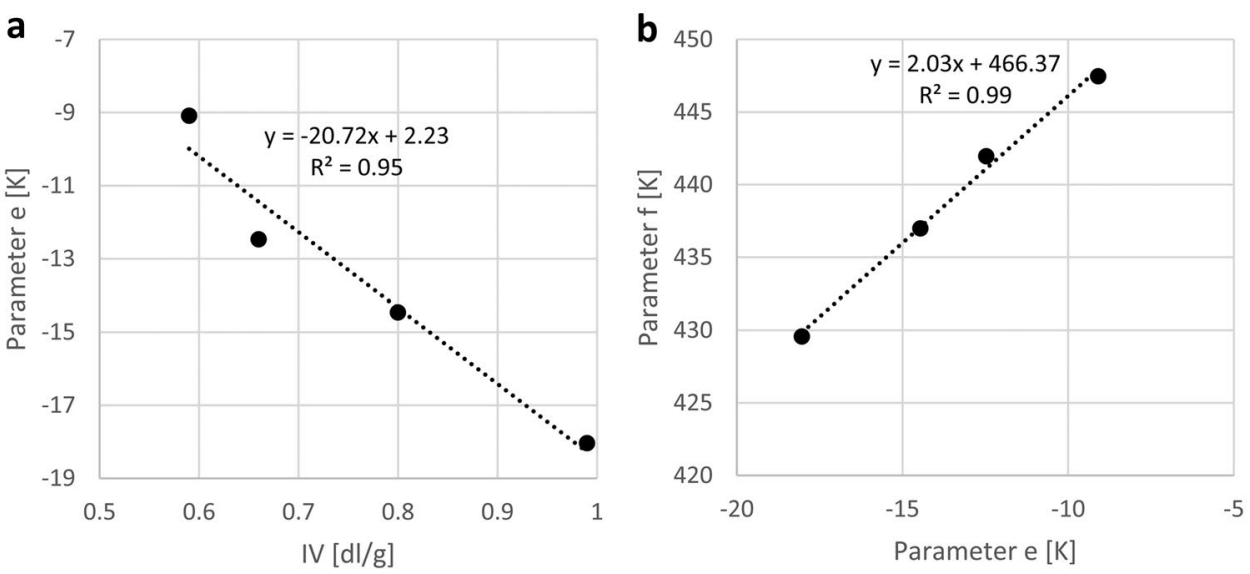

where $\chi_{1}[\%]$ is the crystalline ratio, $T_{m l}[\mathrm{~K}]$ is the melting temperature of the first set, $I V[\mathrm{dl} / \mathrm{g}]$ is the $I V$ value of the examined material and $t_{c}[\mathrm{~h}]$ is the crystallization time.

These evaluation steps were done for all the 5 identified and separated sub-peak sets. The obtained results and establishments are summarized in Table 4. The change in the crystallinity was measured for each set on a specific temperature. It has to be noted that the summarized characteristics are valid only in the investigated range $\left(\mathrm{t}_{\mathrm{c}}<10 \mathrm{~h} ; 393 \mathrm{~K}<\mathrm{T}_{\mathrm{c}}<493 \mathrm{~K}\right)$.

\section{Crystallization processes in different temperature ranges}

It can be seen that sub-peak sets 1, 2 and 3 are formed in lower crystallization temperatures, but the appearance of sub-peak sets 4 and 5 is typical at higher crystallization temperatures. Therefore, these temperature ranges were analysed separately as well.

\section{Sub-peaks appearing at lower crystallization temperature $\left(T_{c}<460 \mathrm{~K}\right)$.}

At low crystallization temperature, under $440 \mathrm{~K}$, only subpeak sets 1 and 3 can be noticed in the DSC thermograms. It is presumed that out of the ordered phases that were formed during the isothermal crystallization sub-peak set 2, which was formed during primer crystallization, completely transformed into the sub-peak set 3 . The sub-peak set 1 , formed during secondary crystallization, only partially transformed into the sub-peak set phase 3 .

By raising the crystallization temperature ( $440-460 \mathrm{~K})$, the sub-peak set 2 transforms into sub-peak set 3 to a lesser extent, therefore it can be detected in larger ratio. Based on the value of the $H$-W slope of sub-peak set 2, lamella thickening is assumed especially in case of lower $I V$, and lamella widening in case of higher $I V$. The formed sub-peak set 2 at higher $T_{c}$ results more stabilised structures, and these structures do not change to other sub-peak sets during the heating. This assumption is in accordance with the findings of

Table 4 Characteristics of the different sub-peak sets

\begin{tabular}{|c|c|c|c|c|c|c|}
\hline & & Sub-peak set 1 & Sub-peak set 2 & Sub-peak set 3 & Sub-peak set 4 & Sub-peak set 5 \\
\hline \multirow[t]{5}{*}{ Crystallinity } & $\begin{array}{l}\text { typical appearance } \\
T_{c} \text { region }\end{array}$ & $<486 \mathrm{~K}$ & $440-470 \mathrm{~K}$ & $<468 \mathrm{~K}$ & $470 \mathrm{~K}<$ & $470 \mathrm{~K}<$ \\
\hline & analysed $T_{c}$ & $423 \mathrm{~K}$ & $453 \mathrm{~K}$ & $423 \mathrm{~K}$ & $483 \mathrm{~K}$ & $483 \mathrm{~K}$ \\
\hline & as a function of $t_{c}$ & logarithmic increase & $\begin{array}{l}\text { increase until } 1 \mathrm{~h} \text {, } \\
\text { then stagnates }\end{array}$ & no significant effect & $\begin{array}{l}\text { logarithmic } \\
\text { decrease }\end{array}$ & logarithmic increase \\
\hline & as a function of $I V$ & no significant effect & no significant effect & increase & no significant effect & no significant effect \\
\hline & $\begin{array}{l}\text { as a function of } \\
\text { heating rate }\end{array}$ & increase & increase & decrease & decrease & increase \\
\hline \multirow[t]{2}{*}{$H$-W slope } & range & $0.95-1.15$ & $0.15-0.70$ & $-0.05-0.00$ & $0.00-0.45$ & $0.60-1.25$ \\
\hline & $\begin{array}{l}\text { as a function of } t_{c} \\
\text { as a function of } I V\end{array}$ & $\begin{array}{l}\text { logarithmic increase } \\
\text { decrease }\end{array}$ & $\begin{array}{l}\text { no significant effect } \\
\text { increase }\end{array}$ & $\begin{array}{l}\text { no significant effect } \\
\text { no significant effect }\end{array}$ & $\begin{array}{l}\text { increase } \\
\text { decrease }\end{array}$ & $\begin{array}{l}\text { no significant effect } \\
\text { increase }\end{array}$ \\
\hline
\end{tabular}




\section{Crystallization}
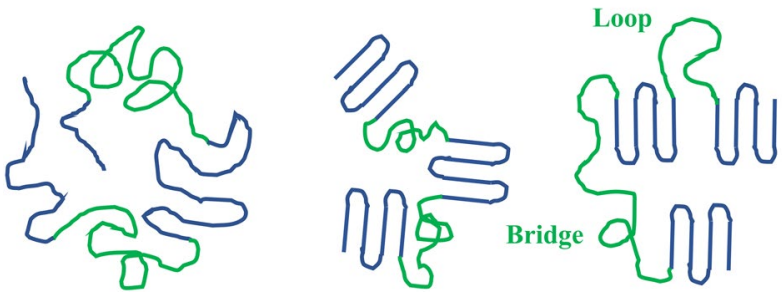

Fig. 13 Multiblock view: crystallization within the molecular chains (based on Liu et al. [42])

Baldenegro-Perez et al. [26], who detected lamella thickening and slight secondary crystallization in this crystallization temperature range by using SAXS and WAXD techniques.

By comparing the characteristics of the different subpeak sets, it can be seen that only the sub-peak set 3 phase is significantly influenced by the $I V$. This also implies that this phase is formed probably not from amorphous phase by nucleation, but it appears as a result of changes (growing/transformation) of already existing crystallites. These changes take place on the loops/bridges; therefore, the chain length plays important role regarding the part ratio of this type of crystalline structure. This result is important in the viewpoint of recycling since secondary PET material usually has lower IV value than original material.

The $H$-W slope of sub-peak set 3 is not influenced by the $I V$. The value of the slope is negative; therefore, it is not interpretable by the thermodynamic laws. This also confirms that the sub-peak set 3 is formed not during the isothermal crystallization, but appears during the heating of the measured samples, and evolves from sub-peak set 1 and 2 .

The behaviour of sub-peak set 2, formed at lower $T_{c}$, can be explained by the adjacent re-entry model and the tightly-folded fashion model [42, 43]. This description mode is based on the intermolecular ordering of the chains and explains the formation of the crystalline layers in a multiblock view. The multiblock view (Fig. 13) describes the formation of the crystallite layers as a formation of folded rigid and amorphous flexible segments on the chains and then their organization [42].

Sub-peak set 2 is formed by the primary folded segments which can get thicker or wider by themselves. However, until their surface/volume ratio is below a critical value, during heating they merge into layers and form sub-peak set 3 . In the ordering of the folded chains the loops/bridges have a crucial role. The longer molecular chains can ensure more'bridges', therefore the part ratio of this sub-set is greater.
Sub-peaks appearing at higher crystallization temperature $\left(T_{c}>460 \mathrm{~K}\right)$.

When $T_{c}$ is higher than $460 \mathrm{~K}$, the nature of nucleation changes. This change is probably due to the more intense moving of the molecules as a result of more thermal energy. In this case, a transitional sub-peak set is formed (sub-peak set 4), the behaviour of which set fits the Strobl model. If $t_{c}$ is short, then sub-peak set 4 can be detected during the measurement. However, in case of longer crystallization time, during the crystallization or recrystallization it transforms into sub-peak set 5 logarithmically as a function of $t_{c}$. Sub-peak set 5 is likely the result of the crystallization of pre-organized mesomorph parts, thereby forming the crystalline layers and lamellas. This transformation does not occur when $t_{c}$ is only $10 \mathrm{~min}$. When $t_{c}$ is between 1 and $3 \mathrm{~h}$ then the transformation is partial, and when $t_{c}$ is more than or equal to $5 \mathrm{~h}$ then it becomes complete.

\section{Applicability of different crystallization models for the sub-sets}

The crystallinity and the formation rate of all sub-peak sets except from sub-peak set 3 are not affected by the $I V$ therefore by the length of the molecular chains. In case of these sub-peak sets, it is more likely that segmental ordering occurs independently from the chain length. This formation may start from chain folding (sub-peak set 2) or from the reorganisation (sub-peak set 1 and 5) of preordered mesomorph parts (sub-peak set 4) according to the Strobl model [17, 44] (Fig. 14). During this reorganisation the inner surface of the organised parts decreases significantly, therefore, changing the surface/volume Helmholtz free energy ratio, and by that the melting temperature [18].

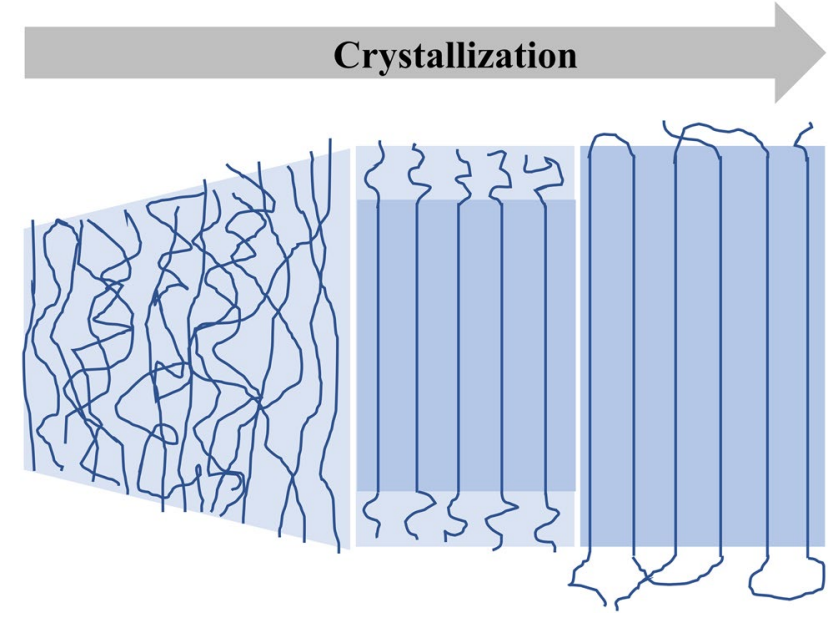

Fig. 14 Strobl crystallization model (based on Strobl and Cho [44]) 
The behaviour of the sub-peak sets 1 and 5 is similar in many ways: their part ratio increases logarithmically as a function of time, and the values of the $H$-W slopes vary in a similar range. The difference between the two sets is that sub-peak set 1 is formed at lower $T_{c}$ and its ratio is significantly smaller. These two sub-peak sets are formed by the parallel ordering of the molecular chains as the Strobl model describes it. In case of PET, this process is more time and energy-demanding than the chain folding.

According to the H-W theory, the $T_{m}$ vs. $T_{c}$ functions are related with the thickening of the structures organised by chain folding. This approach is only applicable on subpeak set 2 . Accordingly, the equilibrium melting temperature $\left(T_{m}{ }^{0}\right)$ could be determined by the analysis of the $H-W$ slopes of this sub-peak set. However, the obtained $T_{m}{ }^{0}$ for this sub-peak set is only a theoretical value since at higher ranges of $T_{c}$ the formed structures in the material are different from the structures of sub-peak set 2 .

\section{Conclusion}

In this research study, the crystalline phases, formed during isothermal crystallization and subsequent heating of PET, were analysed by DSC. Crystallization experiments were performed on PET materials with different molecular weight by varying the temperature and duration of the treatment. Then, the multiple endotherm peaks, appeared on the subsequent heating thermogram, were separated into sub peaks with a novel method and comprehensively analysed.

By analysing the melting temperature as a function of crystallization temperature, five sub-sets were identified and separated (the separated points fall on a straight line). From the thus created Hoffman-Weeks slopes, the mode of crystallization of the different sub-peak set was interpreted. It was concluded that only one (sub-peak set 2) fits the lamella thickening theory, while the Strobl model was found to be more suitable to describe the behaviour of the other sub-peak sets.

By analysing the crystallinity and the melting temperature of the sub-peak sets as a function of crystallization time, temperature and $I V$, it was concluded that different sub-peak sets are formed below and above the crystallization temperature of $460 \mathrm{~K}$. In the lower temperature region, the sub-peak sets that were formed during primary or secondary crystallization are transformed partially or completely to a third sub set during the heating run of the measurement. In the higher temperature region, the sub-peak set formed during primary crystallization gradually transforms to a more stable structure.

The relationship between the crystallinity and the melting temperature of the sub-peak sets were characterised by functions. In the case of sub set 1 , the function was found to be logarithmic, but for sub-peak sets $2-5$, linear fit was found to be adequate in the investigated range: $\mathrm{tc}<10 \mathrm{~h} ; 393 \mathrm{~K}<\mathrm{Tc}<493 \mathrm{~K}$.
Supplementary information The online version contains supplementary material available at (https://doi.org/10.1007/s10965-020-02327-7).

Author contributions Ferenc Ronkay contributed to the study conception and design. Material preparation, data collection and analysis were performed by Béla Molnár, Dóra Nagy and Katalin Bocz. GPC measurements were performed by Györgyi Szarka and Béla Iván, while WAXD measurements were carried out by Ferenc Kristály and Valéria Mertinger. The first draft of the manuscript was written by Ferenc Ronkay and all authors commented on previous versions of the manuscript. All authors read and approved the final manuscript.

Funding Open access funding provided by Budapest University of Technology and Economics. The project was funded by the National Research, Development and Innovation Fund of Hungary in the frame of 2018-1.3.1-VKE-2018-00017 project. The research was funded by the Hungarian Scientific Research Fund, grant number OTKA PD121171 and FK128352. K. Bocz is thankful for the János Bolyai Research Scholarship of the Hungarian Academy of Sciences.

Data Availability All data generated or analysed during this study are included in this published article (and its supplementary information files).

\section{Compliance with ethical standards}

Conflict of interest No potential conflict of interest was reported by the authors.

Open Access This article is licensed under a Creative Commons Attribution 4.0 International License, which permits use, sharing, adaptation, distribution and reproduction in any medium or format, as long as you give appropriate credit to the original author(s) and the source, provide a link to the Creative Commons licence, and indicate if changes were made. The images or other third party material in this article are included in the article's Creative Commons licence, unless indicated otherwise in a credit line to the material. If material is not included in the article's Creative Commons licence and your intended use is not permitted by statutory regulation or exceeds the permitted use, you will need to obtain permission directly from the copyright holder. To view a copy of this licence, visit http://creativecommons.org/licenses/by/4.0/.

\section{References}

1. Zander NE, Gillan M, Lambeth RH (2018) Recycled polyethylene terephthalate as a new FFF feedstock material. Addit Manuf 21:174-182

2. Yin G-Z, Yang X-M (2020) Biodegradable polymers: A cure for the planet, but a long way to go. J Polym Res 27:38

3. Ronkay F, Molnár B, Szalay F, Nagy D, Bodzay B, Sajó IE, Bocz K (2019) Development of Flame-Retarded Nanocomposites from Recycled PET Bottles for the Electronics Industry. Polymers (Basel) 11:233

4. Molnar B, Ronkay F (2019) Effect of solid-state polycondensation on crystalline structure and mechanical properties of recycled polyethylene-terephthalate. Polym Bull 76:2387-2398

5. Ronkay F, Molnar B, Dogossy G (2017) The effect of mold temperature on chemical foaming of injection molded recycled polyethylene-terephthalate. Thermochim Acta 651:65-72 
6. Lai CC, Yu CT, Wang FM, Hsiao HT, Liang WC, Ho YH, Teng WF, Liu LC, Chen CM (2019) Preparation of recycled polyethylene terephthalate composite foams and their feasible evaluation for electronic packages. Polym Test 74:1-6

7. Exconde MKJE, Co JAA, Manapat JZ, Magdaluyo ER (2019) Materials Selection of 3D Printing Filament and Utilization of Recycled Polyethylene Terephthalate (PET) in a Redesigned Breadboard. Procedia CIRP 84:28-32

8. Ronkay F, Molnár B (2017) Time Dependence of Morphology and Mechanical Properties of Injection Molded Recycled PET. Int Polym Process 32:203-208

9. Wang D, Luo F, Luo C (2019) A novel blend material to improve the crystallization and mechanical properties of poly (ethylene terephthalate). J Polym Res 26:170

10. Szegő L (1979) Modified polyethylene-terephthalate fibers. Adv Polym Sci. https://doi.org/10.1007/BFb0103461

11. Jabarin SA (1987) Crystallization kinetics of polyethylene-terephthalate. I. Isothermal crystallization from the melt. J Appl Polym Sci 34:85-96

12. Chen Z (2012) The Crystallization of Poly (ethylene terephthalate) Studied by Thermal Analysis and FTIR Spectroscopy Doctor of Philosophy. University of Birmingham, University of Birmingham

13. Demirel B, Yaraș A, Elçiçek H (2011) Crystallization behavior of PET materials. BAÜ Fen Bil Enst Derg Cilt 13:26-35

14. Perez M (2005) Gibbs-Thomson effects in phase transformations. Scr Mater 52:709-712

15. Lu X, Hay J (2001) Isothermal crystallization kinetics and melting behaviour of poly(ethylene-terephthalate). Polymer (Guildf) 42:9423-9431

16. Xu J, Heck B, Ye HM, Jiang J, Tang YR, Liu J, Guo BH, Reiter R, Zhou DS, Reiter G (2016) Stabilization of nuclei of lamellar polymer crystals: Insights from a comparison of the Hoffman-Weeks line with the crystallization line. Macromolecules 49:2206-2215

17. Strobl G (2000) From the melt via mesomorphic and granular crystalline layers to lamellar crystallites: A major route followed in polymer crystallization? Eur Phys J E 3:165-183

18. Wurm A, Schick C (2002) Development of thermal stability of polymer crystals during isothermal crystallization. E-Polymers $2: 1-15$

19. Van Antwerpen F, Van Krevelen DW (1972) Influence of crystallization temperature, molecular weight and additives on the crystallization kinetics of poly(ethylene-terephthalate). J Polym Sci 10:2423-2435

20. Woo EM, Ko TY (1996) A differential scanning calorimetry study on poly(ethylene-terephthalate) isothermally crystallized at stepwise temperatures: Multiple melting behavior re-investigated. Colloid Polym Sci 274:309-315

21. Sauer B, Kampert W, Neal Blanchard E, Threefoot S, Hsiao B (2000) Temperature modulated DSC studies of melting and recrystallization in polymers exhibiting multiple endotherms. Polymer (Guildf) 41:1099-1108

22. Kong Y, Hay JN (2003) Multiple melting behaviour of poly(ethylene-terephthalate). Polymer (Guildf) 44:623-633

23. Mathot V, Pyda M, Pijpers T, Vanden Poel G, van de Kerkhof E, van Herwaarden S, van Herwaarden F, Leenaers A (2011) The Flash DSC 1, a power compensation twin-type, chip-based fast scanning calorimeter (FSC): First findings on polymers. Thermochim Acta 522:36-45

24. Bell JP, Murayama T (1969) Relations between dynamic mechanical properties and melting behavior of nylon 66 and poly ethylene terephthalate. J Polym Sci Part A-2 Polym Phys 7:1059-1073

25. Melnikov AP, Rosenthal M, Rodygin AI, Doblas D, Anokhin DV, Burghammer M, Ivanov DA (2016) Re-exploring the double-melting behavior of semirigid-chain polymers with an in-situ combination of synchrotron nano-focus X-ray scattering and nanocalorimetry. Eur Polym J 81:598-606
26. Baldenegro-Perez LA, Navarro-Rodriguez D, Medellin-Rodriguez FJ, Hsiao B, Avila-Orta CA, Sics I (2014) Molecular weight and crystallization temperature effects on poly(ethylene-terephthalate) (PET) homopolymers, an isothermal crystallization analysis. Polymers (Basel) 6:583-600

27. Chen Z, Hay JN, Jenkins MJ (2012) FTIR spectroscopic analysis of poly(ethylene-terephthalate) on crystallization. Eur Polym J 48:1586-1610

28. Roberts RC (1970) The melting behavior of bulk crystallized polymers. J Polym Sci Part B Polym Lett 8:381-384

29. Sweet GE, Bell JP (1972) Multiple endotherm melting behavior in relation to polymer morphology. J Polym Sci Part A-2 Polym Phys 10:1273-1283

30. Roeninckx G, Reynaers H, Berghmans H, Smets G (1980) Morphology and melting behavior of semicrystalline poly(ethyleneterephthalate). II, Annealed PET, p 18

31. Zhou C, Clough SB (1988) Multiple melting endotherms of poly(ethylene terephthalate). Polym Eng Sci 28:65-68

32. Medellín-Rodríguez FJ, Phillips PJ, Lin JS (1996) Melting behavior of high-temperature polymers. Macromolecules 29:7491-7501

33. Rodriguez F, Phillips PJ, Lin J, Campos R (1997) The triple melting behavior of poly(ethylene-terephthalate). J Polym Sci Part B Polym Phys 35:1757-1774

34. Tan S, Su A, Li W, Zhou E (1998) The crystallization behavior of the metastable melts of poly(ethylene terephthalate) from the multiple melting process. Macromol Rapid Commun 19:11-14

35. Wang ZG, Hsiao BS, Fu BX, Liu L, Yeh F, Sauer BB, Chang H, Schultz JM (2000) Correct determination of crystal lamellar thickness in semicrystalline poly(ethylene terephthalate) by smallangle X-ray scattering. Polymer (Guildf) 41:1791-1797

36. Wu H, Lv S, He Y, Qu JP (2019) The study of the thermomechanical degradation and mechanical properties of PET recycled by industrial-scale elongational processing. Polym Test 77:105882

37. Sanches NB, Dias ML, Pacheco EBAV (2005) Comparative techniques for molecular weight evaluation of poly(ethylene-terephthalate) (PET). Polym Test 24:688-693

38. Badia JD, Strömberg E, Karlsson S, Ribes-Greus A (2012) The role of crystalline, mobile amorphous rigid amorphous fractions in the performance of recycled poly(ethylene-terephthalate) (PET). Polym Degrad Stab 97:98-107

39. Al RM (1994) Morphology and crystallization poly(ethyleneterephthalate). Polym Int 35:189-195

40. Tan S, Su A, Li W, Zhou E (2000) New insight into melting and crystallization behavior in semicrystalline poly(ethylene terephthalate). J Polym Sci Part B Polym Phys 38:53-60

41. Yagfarov AS (1988) The nature of secondary crystallization in polymers. Polym Sci USSR 30:88-95

42. Liu F, Sun T, Tang P, Zhang H, Qiu F (2017) Understanding chain folding morphology of semicrystalline polymers based on a rodcoil multiblock model. Soft Matter 13:8250-8263

43. Zhang M, Guo B-H, Xu J (2016) A review on polymer crystallization theories. Crystals 7:4-18

44. Strobl G, Cho TY (2007) Growth kinetics of polymer crystals in bulk. Eur Phys J E 23:55-65

Publisher's Note Springer Nature remains neutral with regard to jurisdictional claims in published maps and institutional affiliations. 